\title{
Antifungal Drug Susceptibility and Genetic Characterization of Fungi Recovered from COVID-19 Patients
}

\author{
Milena Kordalewska ${ }^{1}{ }^{*}$, Kevin D. Guerrero ${ }^{1}$, Rocio Garcia-Rubio ${ }^{1}{ }^{10}$, Cristina Jiménez-Ortigosa ${ }^{1}$, \\ José R. Mediavilla ${ }^{1}$, Marcus H. Cunningham ${ }^{1}$, Frank Hollis ${ }^{2}$, Tao Hong ${ }^{2}$, Kar Fai Chow ${ }^{2}$, Barry N. Kreiswirth ${ }^{1}$ \\ and David S. Perlin ${ }^{1}$ \\ 1 Center for Discovery and Innovation, Hackensack Meridian Health, Nutley, NJ 07110, USA; \\ kevin.guerrero@hmh-cdi.org (K.D.G.); rocio.garciarubio@hmh-cdi.org (R.G.-R.); \\ cristina.jimenez-ortigosa@hmh-cdi.org (C.J.-O.); jose.mediavilla@hmh-cdi.org (J.R.M.); \\ marcus.cunningham@hmh-cdi.org (M.H.C.); barry.kreiswirth@hmh-cdi.org (B.N.K.); \\ david.perlin@hmh-cdi.org (D.S.P.) \\ 2 Hackensack University Medical Center, Hackensack, NJ 07601, USA; fhollis@optonline.net (F.H.); \\ Tao.Hong@hmhn.org (T.H.); Kar.Chow@hmhn.org (K.F.C.) \\ * Correspondence: milena.kordalewska@hmh-cdi.org; Tel.: +1-(201)-880-3505
}

Citation: Kordalewska, M.; Guerrero, K.D.; Garcia-Rubio, R.;

Jiménez-Ortigosa, C.; Mediavilla, J.R.; Cunningham, M.H.; Hollis, F.; Hong,

T.; Chow, K.F.; Kreiswirth, B.N.; et al. Antifungal Drug Susceptibility and Genetic Characterization of Fungi Recovered from COVID-19 Patients. J Fungi 2021, 7, 552. https://doi.org/ 10.3390/jof7070552

Academic Editor:

Ana Alastruey-Izquierdo

Received: 8 May 2021

Accepted: 10 July 2021

Published: 11 July 2021

Publisher's Note: MDPI stays neutral with regard to jurisdictional claims in published maps and institutional affiliations.

Copyright: (c) 2021 by the authors Licensee MDPI, Basel, Switzerland. This article is an open access article distributed under the terms and conditions of the Creative Commons Attribution (CC BY) license (https:/ / creativecommons.org/licenses/by/ $4.0 /)$.
Abstract: Fungal infections are common complications of respiratory viral infections and are associated with the increased need for intensive care and elevated mortality. Data regarding microbiological and molecular characteristics of such infections in COVID-19 patients are scarce. Here, we performed a comprehensive analysis, including species identification, antifungal susceptibility testing, molecular resistance determinants analysis, typing, and retrospective clinical data review, of fungal isolates recovered from 19 COVID-19 patients, who were hospitalized at the Hackensack University Medical Center (HUMC) in Hackensack, New Jersey, USA, in the initial phase of the pandemic from April-May 2020. In total, 17 Candida albicans, two C. parapsilosis, and two Aspergillus fumigatus were analyzed. All Candida spp. isolates were susceptible to micafungin and azole drugs (fluconazole, voriconazole, posaconazole, itraconazole, isavuconazole). A. fumigatus isolates were susceptible to micafungin and all triazole drugs except fluconazole (intrinsic resistance). Multilocus sequence typing (MLST) of C. albicans isolates revealed 15 different sequence types (STs), which clustered below the clade-defining limit of p-distance $<0.04$. Pulsed-field gel electrophoresis (PFGE) karyotyping revealed no chromosomal rearrangements in these isolates. A. fumigatus isolates were of different, non-related genotypes. We speculate that virus- and drug-induced immunosuppression $(94.7 \%$ of the patients received corticosteroids), together with prolonged hospital stay (median duration of 29 days) and mechanical ventilation (median duration of 24 days) likely increased the susceptibility to secondary respiratory and bloodstream infections in the studied patient population. The presence of fungi in blood or respiratory tract fluid was a prognosticator for poor clinical outcome, which presented as an $89.5 \% 30$-day mortality in our patient cohort.

Keywords: Candida albicans; Candida parapsilosis; Aspergillus fumigatus; antifungal susceptibility; secondary infections; Candida pneumonia; candidiasis; aspergillosis; COVID-19-associated candidemia; COVID-19

\section{Introduction}

The emergence and subsequent pandemic of coronavirus disease 2019 (COVID-19), caused by severe acute respiratory syndrome coronavirus 2 (SARS-CoV-2), has led to a global public health crisis with $154.6 \mathrm{M}+$ confirmed cases and 3.2M+ deaths worldwide (as of 6 May 2021) [1]. The relatively high incidence of severe disease and mortality in COVID-19 patients is expected to be enhanced by secondary infections, alongside a lack of natural immunity and viral replication in the lower respiratory tract leading to severe lung injury and acute respiratory distress syndrome (ARDS). Bacterial and fungal infections are common complications of viral pneumonia which lead to an increased need for 
intensive care and higher mortality rates. Superinfections with Streptococcus pneumoniae, Staphylococcus aureus, and Haemophilus influenzae are well-known complications of severe seasonal and pandemic influenza [2]. More recently, invasive pulmonary aspergillosis (IPA) has been described as a confounder in critically ill patients admitted to the intensive care unit (ICU) with influenza pneumonia [3]. According to the cohort study report by Zheng et al., 20 out of 90 patients with the severe acute respiratory syndrome (SARS) had secondary lower respiratory tract infections in 2003, which accounted for $70.6 \%$ of critical SARS patients who underwent an invasive operation. There was a large diversity of pathogens causing secondary infections in SARS patients, with Gram-negative bacteria and Candida spp. being the most common ones [4]. Some cases were complicated by invasive fungal disease-aspergillosis [5]—especially in patients receiving corticosteroids [6].

In Wuhan, China, secondary infections have been identified in 14 to $38 \%$ of hospitalized patients with COVID-19, of whom, 50\% did not survive [7]. In New York City, bacteremia developed in $5.6 \%$ of all patients and $11.9 \%$ of patients requiring invasive mechanical ventilation [8]. Importantly, researchers also identified a number of secondary fungal co-infections in hospitalized COVID-19 patients [9-13]. A French study found putative IPA in almost one-third of mechanically ventilated patients with COVID-19-a similar prevalence to that observed in patients with influenza [14].

In this context, some authors have speculated that there might exist two non-mutually exclusive explanations for the presence of superinfections in COVID-19 patients [15]. Firstly, severe SARS-CoV-2 infection results in immune system dysregulation [16,17]. Cytokine release syndrome, immune exhaustion, and/or lung damage may leave patients vulnerable to bacterial and/or fungal superinfections [15]. Secondly, critically ill patients, especially those in ICUs and/or receiving mechanical ventilation, are at markedly increased risk for bacterial and fungal infections, independent of COVID-19 [15]. Among COVID-19 ICU patients, mechanical ventilation was reported in $21 \%-88 \%$ of cases [8,18-22].

Given its very recent emergence, data regarding secondary fungal infections in COVID19 patients are scarce. Thus, it is crucial to understand the clinical and microbiological characteristics of such infections, especially the causal species distribution, the source of infection (nosocomial vs. community-acquired), as well as the antifungal drug susceptibility, to implement appropriate infection prevention measures and/or treatment regimens. Here, we performed a comprehensive analysis (species identification, antifungal susceptibility testing with molecular resistance determinants analysis, and typing) of fungal isolates recovered from COVID-19 patients, who were hospitalized at the Hackensack University Medical Center (HUMC) in Hackensack, NJ, USA.

\section{Materials and Methods}

\subsection{Fungal Isolates and Culture Conditions}

We used a total of 21 clinical isolates of fungi (yeasts, $n=19$; molds, $n=2$ ), which were recovered from specimens (blood, $n=11$; sputum, $n=10$ ) of 19 COVID-19 patients at the Department of Pathology at Hackensack University Medical Center (HUMC) in Hackensack, NJ, USA, in April and May 2020 (Table 1). Yeast and mold isolates were cultured on yeast extract $(1 \%)$ peptone $(2 \%)$ dextrose $(1 \%)$ agar (YPDA), and potato dextrose agar (PDA) plates, respectively, at $37{ }^{\circ} \mathrm{C}$ prior to testing. Species identification of all yeast isolates was performed by sequencing the rDNA region (Table 2) and further Nucleotide BLAST (https: / / blast.ncbi.nlm.nih.gov/Blast.cgi; accessed on 9 June 2020) analysis. Confirmation of Aspergillus fumigatus species identification was performed by PCR amplification and sequencing of a portion of the $\beta$-tubulin gene (Table 2) followed by Nucleotide BLAST analysis. 
Table 1. Results of identification, antifungal susceptibility testing, and antifungal drug target sequencing for fungal isolates recovered from COVID-19 patients.

\begin{tabular}{|c|c|c|c|c|c|c|c|c|c|c|c|}
\hline \multirow[b]{2}{*}{ Isolate } & \multirow[b]{2}{*}{ Specimen } & \multicolumn{2}{|c|}{ Identification } & \multicolumn{6}{|c|}{$\mathrm{MIC}[\mathrm{mg} / \mathrm{L}]{ }^{*}$} & \multirow[b]{2}{*}{ FKS1 } & \multirow[b]{2}{*}{ Erg11/Сур51А } \\
\hline & & $\begin{array}{c}\text { Original } \\
\text { (at HUMC) }\end{array}$ & $\begin{array}{c}\text { Species } \\
\text { Confirmation } \\
\text { (rDNA seq) }\end{array}$ & MCF & FLC & VRC & ITR & POS & ISA & & \\
\hline MB 004 & Blood & C. albicans & C. albicans & $<0.03$ & $<0.25$ & 0.03 & $<0.03$ & $<0.03$ & $<0.03$ & WT & E266D \\
\hline MB 013 & Blood & C. albicans & C. albicans & $<0.03$ & 0.25 & 0.03 & 0.03 & 0.03 & 0.03 & WT & $\begin{array}{l}\text { V437I } \\
\text { E266D, }\end{array}$ \\
\hline MB 026 & Blood & C. albicans & C. albicans & $<0.03$ & 0.25 & 0.03 & $<0.03$ & $<0.03$ & $<0.03$ & WT & $\begin{array}{l}\mathrm{H} 283 \mathrm{H} / \mathrm{L} \\
\mathrm{K} 342 \mathrm{~K} / \mathrm{R}\end{array}$ \\
\hline MB 030 & Blood & C. albicans & C. albicans & $<0.03$ & 0.25 & 0.03 & 0.03 & $<0.03$ & $<0.03$ & WT & V437V/I \\
\hline MB 044 & Sputum & yeast & C. albicans & $<0.03$ & 0.25 & 0.03 & 0.03 & $<0.03$ & $<0.03$ & WT & $\mathrm{K} 128 \mathrm{~K} / \mathrm{T}$ \\
\hline MB 047 & Sputum & yeast & C. albicans & $<0.03$ & 0.25 & 0.03 & 0.03 & $<0.03$ & $<0.03$ & WT & $\mathrm{K} 128 \mathrm{~K} / \mathrm{T}$ \\
\hline MB 056 & Sputum & yeast & C. albicans & $<0.03$ & 0.25 & 0.03 & 0.03 & $<0.03$ & $<0.03$ & WT & V437V/I \\
\hline MB 059 & Sputum & $\begin{array}{c}\text { yeast (not } \\
\text { Cruptococcus) }\end{array}$ & C. albicans & $<0.03$ & 0.25 & 0.03 & 0.03 & $<0.03$ & $<0.03$ & WT & $\mathrm{K} 128 \mathrm{~K} / \mathrm{T}$ \\
\hline MB 060 & Sputum & yeast & C. albicans & $<0.03$ & 0.25 & 0.03 & 0.03 & $<0.03$ & $<0.03$ & WT & $\mathrm{K} 128 \mathrm{~K} / \mathrm{T}$ \\
\hline MB 064 & Sputum & $\begin{array}{c}\text { yeast (not } \\
\text { Cryptococcus) }\end{array}$ & C. albicans & $<0.03$ & 0.25 & 0.03 & 0.03 & $<0.03$ & $<0.03$ & WT & $\begin{array}{l}\text { D116D/E, } \\
\text { E266E/D }\end{array}$ \\
\hline MB 092 & Blood & C. albicans & C. albicans & $<0.03$ & $<0.25$ & 0.03 & 0.03 & $<0.03$ & $<0.03$ & WT & V437V/I \\
\hline MB 096 & Blood & C. albicans & C. albicans & $<0.03$ & 0.25 & 0.03 & 0.03 & $<0.03$ & $<0.03$ & WT & $\begin{array}{l}\text { D116E, } \\
\mathrm{K} 128 \mathrm{~K} / \mathrm{T}\end{array}$ \\
\hline MB 114 & Blood & C. albicans & C. albicans & $<0.03$ & 0.25 & 0.03 & 0.03 & $<0.03$ & $<0.03$ & WT & $\begin{array}{l}\text { E266E/D, } \\
\text { V437V/I }\end{array}$ \\
\hline MB 167 & Blood & C. albicans & C. albicans & $<0.03$ & 0.25 & 0.03 & 0.03 & $<0.03$ & $<0.03$ & WT & D116E, K128T \\
\hline MB 168 & Blood & C. albicans & C. albicans & $<0.03$ & 0.25 & 0.03 & 0.03 & $<0.03$ & $<0.03$ & WT & $\begin{array}{l}\mathrm{V} 437 \mathrm{~V} / \mathrm{I} \\
\mathrm{D} 116 \mathrm{D} / \mathrm{E}\end{array}$ \\
\hline MB 179 & Sputum & $\begin{array}{c}\text { yeast (not } \\
\text { Cryptococcus) }\end{array}$ & C. albicans & $<0.03$ & 0.25 & 0.03 & 0.03 & $<0.03$ & $<0.03$ & WT & $\begin{array}{l}\mathrm{K} 128 \mathrm{~K} / \mathrm{T}, \\
\mathrm{V} 159 \mathrm{~V} / \mathrm{I}\end{array}$ \\
\hline MB 180 & Sputum & $\begin{array}{c}\text { yeast (not } \\
\text { Cryptococcus) }\end{array}$ & C. albicans & $<0.03$ & $<0.25$ & 0.06 & $<0.03$ & $<0.03$ & $<0.03$ & WT & $\begin{array}{l}\mathrm{D} 116 \mathrm{D} / \mathrm{E} \\
\mathrm{K} 128 \mathrm{~K} / \mathrm{T}\end{array}$ \\
\hline MB 025 & Blood & C. parapsilosis & C. parapsilosis & 2 & 0.5 & 0.125 & $<0.03$ & $<0.03$ & $<0.03$ & $\mathrm{WT} * *$ & F215S \\
\hline MB 099 & Blood & C. parapsilosis & C. parapsilosis & 2 & 0.5 & 0.125 & $<0.03$ & $<0.03$ & $<0.03$ & $\mathrm{WT} * *$ & $\mathrm{~F} 215 \mathrm{~S}$ \\
\hline MB 097 & Sputum & A. fumigatus & A. fumigatus & 0.06 & $>64$ & 0.25 & 0.5 & 0.03 & 0.125 & N/A & WT \\
\hline MB 098 & Sputum & A. fumigatus & A. fumigatus & 0.06 & $>64$ & 0.25 & 0.5 & 0.03 & 0.125 & $\mathrm{~N} / \mathrm{A}$ & WT \\
\hline
\end{tabular}

${ }^{*}$ MEC in case of MCF and A. fumigatus clinical isolates. ${ }^{* *}$ C. parapsilosis WT contains a naturally occurring polymorphism in the last amino acid of the hot spot 1 .

\subsection{DNA Extraction}

DNA from fungal isolates was prepared by a 10-min incubation of a single colony in $100 \mu \mathrm{L}$ of extraction buffer $\left(60 \mathrm{mM}\right.$ sodium bicarbonate $\left[\mathrm{NaHCO}_{3}\right], 250 \mathrm{mM}$ potassium chloride [KCl], and $50 \mathrm{mM}$ Tris, $\mathrm{pH}$ 9.5) at $95^{\circ} \mathrm{C}$ and subsequent addition of $100 \mu \mathrm{L}$ antiinhibition buffer ( $2 \%$ bovine serum albumin). After vortex mixing, this DNA-containing solution was used for PCR [23].

\subsection{Antifungal Susceptibility Testing}

Antifungal susceptibility testing for yeast isolates was performed in accordance with the guidelines described in CLSI documents M27 and M60 [24,25]. C. parapsilosis ATCC 22019 and C. krusei ATCC 6258 were used as quality control strains.

Antifungal susceptibility testing for mold isolates was performed in accordance with the guidelines described in CLSI documents M38 and M61 [26,27]. A. terreus ATCC MYA3633 and A. flavus ATCC 204304 were used as quality control strains.

Micafungin (MCF), isavuconazole (ISA) (Astellas Pharma US, Inc., Northbrook, IL, USA), fluconazole (FLC) (LKT Laboratories, Inc., St. Paul, MN, USA), itraconazole (ITR), posaconazole (POS), and voriconazole (VRC) (MilliporeSigma, St. Louis, MO, USA) were obtained as standard powders from their manufacturers, and stock solutions were prepared by dissolving the compounds in $100 \%$ dimethyl sulfoxide (DMSO). Minimal inhibitory concentration (MIC) end-points were defined as the lowest drug concentration that caused a prominent decrease $(\geq 50 \%)$ in visual growth in relation to the controls. Micafungin 
minimum effective concentration (MEC) values for molds were read as the lowest drug concentration at which small, rounded, and compact hyphal forms (rosettes) were observed.

\subsection{Sequencing of FKS1 and ERG11}

FKS1 gene, encoding the echinocandin drug target, and ERG11 gene, encoding the azole drug target, of all yeast isolates were amplified and sequenced (Table 2). The full coding sequence of the cyp51A gene, including its promoter sequence, was amplified and sequenced (Table 2) using the PCR conditions described before [28]. DNA cyp51A sequences were compared to the cyp51A sequence of the A. fumigatus reference strain CBS 144.89 (GenBank accession number AF338659) by using SeqMan Pro 17 (DNASTAR Lasergene).

\subsection{Karyotyping of C. albicans Isolates}

Intact yeast chromosomal DNA was prepared as described by Bai et al. [29]. For karyotyping purposes, the chromosomal DNA bands were separated on $0.8 \%$ agarose gels in 1X TAE buffer in a contour-clamped homogeneous electric field (CHEF) electrophoresis system (Bio-Rad, Hercules, CA, USA). Electrophoresis was performed at $2 \mathrm{~V} / \mathrm{cm}$ for $72 \mathrm{~h}$ with initial and final switch times of 2 and $30 \mathrm{~min}$, respectively. The temperature of the running buffer was maintained at $14{ }^{\circ} \mathrm{C}$. After electrophoresis, the gel was stained in ethidium bromide solution $(0.5 \mu \mathrm{g} / \mathrm{mL})$ for $30 \mathrm{~min}$ and photographed under UV illumination. C. albicans SC5314 and ATCC90028 were used as reference strains, and Hansenula wingei (YB-4662-VIA) chromosomal DNA (Bio-Rad, Hercules, CA, USA) was used as a chromosome size marker.

\subsection{Multilocus Sequence Typing (MLST) of C. albicans Isolates}

MLST was performed following a protocol optimized by Bougnoux et al. which comprises an analysis of a set of seven gene fragments: AAT1a, ACC1, ADP1, MPI, SYA1, $V P S 13$, and ZWF1b [30]. The allelic status (homozygote or heterozygote) of each nucleotide was analyzed using SeqMan Pro 17 (DNASTAR Lasergene). Moreover, the DNA sequences of the seven housekeeping genes got concatenated for each isolate and a dendrogram was constructed based on Clustal Omega alignment using MegAlign Pro 17 (DNASTAR Lasergene). A cutoff P distance of 0.04 was chosen to delimit clusters of closely related strain types [31].

\subsection{Typing of A. fumigatus Isolates}

The A. fumigatus isolates included in this study were genotyped following the previously described TRESPERG genotyping assay, which involves sequence analysis of 4 genetic markers: MP-2 antigenic galactomannan protein (MP2; Afu2g05150), a hypothetical protein with a CFEM domain (CFEM; Afu6g14090), cell surface protein A (CSP; Afu3g08990), and putative C-24 sterol reductase (ERG4B; Afu1g07140) (Table 2) [32].

\subsection{Clinical Data Review}

All fungal isolates were de-identified (patient information removed) and given unique HMH BioRepository numbers which enabled to link them to the clinical information. Clinical data, including patient demographics, comorbidities, laboratory tests results, treatment, and outcomes were retrieved from the HMH electronic health record system and reviewed retrospectively. As suggested by Garcia-Vidal et al., infections were defined as community-acquired co-infections if a diagnosis was made at the time of or within the first $24 \mathrm{~h}$ of COVID-19 hospital admission. If a diagnosis occurred $\geq 48 \mathrm{~h}$ after admission for COVID-19, these infections were defined as hospital-acquired superinfections [9].

The study received Hackensack University Medical Center Institutional Review Board approval (Study ID: Pro2018-1022 approved on 19 February 2019). 
Table 2. Primers used in the study.

\begin{tabular}{|c|c|c|c|c|c|}
\hline Gene & Organism & Primer Name & Sequence & Use & Reference \\
\hline \multirow{2}{*}{$r D N A$} & \multirow{2}{*}{ Candida spp. } & Fun-rDNAF & GGTCATTTAGAGGAAGTAAAAGTCG & PCR + seq & \multirow{2}{*}{$\begin{array}{l}\text { S. Katiyar, personal } \\
\text { communication }\end{array}$} \\
\hline & & Fun-rDNAR & YGATATGCTTAAGTTCAGCGGGTA & PCR + seq & \\
\hline \multirow{2}{*}{$\beta$-tubulin } & \multirow{2}{*}{ Aspergillus spp. } & btub2F & TTCACCTTCAGACCGGT & PCR + seq & \multirow{2}{*}{ [33] } \\
\hline & & btub4R & AGTTGTCGGGACGGAATAG & PCR + seq & \\
\hline \multirow{8}{*}{ FKS1 } & \multirow{4}{*}{ C. albicans } & F2426 & CATTGCTGTGGCCACTTTAG & PCR + seq & \multirow{6}{*}{ [34] } \\
\hline & & R2919 & GATTTCCATTTCCGTGGTAGC & PCR & \\
\hline & & F4590 & TACTATGGTCATCCAGGTTTCC & PCR + seq & \\
\hline & & R4954 & GGTCAAATCAGTGAAAACCG & PCR & \\
\hline & \multirow{4}{*}{ C. parapsilosis } & CparF & CTCCAAGTCCTCATATGCAC & PCR + seq & \\
\hline & & CparR & AGATGTTTCTCCATGGTGTC & PCR & \\
\hline & & F4500 & AAGATTGGTGCTGGTATGGG & PCR + seq & \multirow{2}{*}{ [35] } \\
\hline & & R5112 & TAATGGTGCTTGCCAATGAG & PCR & \\
\hline \multirow{8}{*}{ ERG11 } & \multirow{4}{*}{ C. albicans } & Ca_ERG11_F & ATG GCT ATT GTT GAA ACT GTC ATT G & PCR & \multirow{8}{*}{ This study* } \\
\hline & & Ca_ERG11_R & TTA AAA CAT ACA AGT TTC TCT TTT TTC CC & PCR & \\
\hline & & Ca_ERG11_731-750_F & GGA GAC GTG ATG CTG CTC AA & seq & \\
\hline & & Ca_ERG11_918-938_R & GCA GAA GTA TGT TGA CCA CCC & seq & \\
\hline & \multirow{4}{*}{ C. parapsilosis } & Cpara_erg11_F1 & TCCСТACСTTCGTTCATC & PCR + seq & \\
\hline & & Cpara_erg11_R1 & CGAGGTGAGTCAACAAAG & PCR + seq & \\
\hline & & Cpara_erg11_F2 & AGAGACGGGTGACATTG & seq & \\
\hline & & Cpara_erg11_R2 & TGGCACTAGTATGCTGTC & seq & \\
\hline \multirow{2}{*}{$\begin{array}{l}\text { CYP51A } \\
\text { promoter }\end{array}$} & \multirow{2}{*}{ A. fumigatus } & A5 & CTT TTT CGA CTG CCG CGC & PCR + seq & \multirow{7}{*}{ [28] } \\
\hline & & A7 & TCA TAT GTT GCT CAG CGG & PCR + seq & \\
\hline \multirow{5}{*}{ CYP51A } & \multirow{5}{*}{ A. fumigatus } & P450.1 & ATG GTG CCG ATG CTA TGG & PCR & \\
\hline & & $\mathrm{P} 450.2$ & CTG TCT CAC TTG GAT GTG & PCR & \\
\hline & & CypA1 & CTT ACG GCC TAC ATG GCC & seq & \\
\hline & & СурА2 & TTC GAC CGC TTC TCC CAG & seq & \\
\hline & & A3 & TAG TCC ATT GAC GAC CCC & seq & \\
\hline \multirow{10}{*}{$\begin{array}{l}\text { TRESPERG } \\
\text { genotyping }\end{array}$} & \multirow{10}{*}{ A. fumigatus } & CSP1F & TTGGGTGGCATTGTGCCAA & PCR + seq & \multirow{10}{*}{ [32] } \\
\hline & & CSP2R & GAGCATGACAACCCAGATACCA & PCR + seq & \\
\hline & & MP2A & ATGCGGTTCTCTGCGTTA & PCR & \\
\hline & & MP2B & CAGCAACAGTGCAAATGC & PCR & \\
\hline & & MP2_P1 & CTCGAACTTGGCTACGAC & seq & \\
\hline & & MP2_P2 & AGGTAGTGGAGGTCACTG & seq & \\
\hline & & CFEMA & ATGAAGGCCTCTGTGTC & PCR + seq & \\
\hline & & CFEMB & AGGATAATCAAGGCAGCG & PCR + seq & \\
\hline & & ERG4B_P1 & ATGACTGTCACACGCTCC & PCR + seq & \\
\hline & & ERG4B_P2 & TAGACGGCACCAATCCAC & PCR + seq & \\
\hline
\end{tabular}

* Primers were designed on the basis of reference ERG11 sequences: C. albicans_C5_00660C_A; C. parapsilosis-CPAR2_303740.

\section{Results}

\subsection{Species Distribution of Fungal Isolates Recovered from COVID-19 Patients}

Twenty-one fungal isolates were cultured from specimens of COVID-19 patients and archived at The Department of Pathology (HUMC) in April and May 2020. Among 19 yeast isolates, 11 isolates recovered from blood were identified to the species level (9/11 C. albicans; $2 / 11$ C. parapsilosis). Their species were also confirmed by sequencing of rDNA fragments. The remaining 8 isolates, recovered from sputum, were not identified to the species level at the Department of Pathology (HUMC) and labeled as "yeast" or "yeast, not Cryptococcus". These isolates were further identified as $C$. albicans by sequencing of rDNA fragments (Table 1). The two mold isolates recovered from sputum were species-identified as $A$. fumigatus. 


\subsection{Antifungal Susceptibility Testing and Molecular Resistance Determinants Analysis}

AFST with echinocandin and azole drugs was performed for all clinical isolates. The MIC results for each isolate are shown in Table 1. All $17 \mathrm{C}$. albicans isolates presented low MIC values $\left(\mathrm{MIC}_{90}\right.$ : MCF < $0.03 \mathrm{mg} / \mathrm{L}$; FLC $0.25 \mathrm{mg} / \mathrm{L}$; VRC $0.03 \mathrm{mg} / \mathrm{L}$; ITR $0.03 \mathrm{mg} / \mathrm{L}$; POS $<0.03 \mathrm{mg} / \mathrm{L} ;$ ISA $<0.03 \mathrm{mg} / \mathrm{L}$ ). Moreover, sequencing of the gene encoding the echinocandin drug target, $F K S 1$, indicated a wild-type genotype of all isolates. Sequencing of the gene encoding the azole drug target, ERG11, revealed the presence of several hetero- and homozygous mutations (Table 1). The two C. parapsilosis isolates had an MCF MIC value of $2 \mathrm{mg} / \mathrm{L}$ and WT FKS1 genotype, low azole MIC values (same values for both isolates; FLC $0.5 \mathrm{mg} / \mathrm{L}$; VRC $0.125 \mathrm{mg} / \mathrm{L}$; ITR $<0.03 \mathrm{mg} / \mathrm{L} ; \mathrm{POS}<0.03 \mathrm{mg} / \mathrm{L}$; ISA $<0.03 \mathrm{mg} / \mathrm{L}$ ) and the F215S amino acid change was found in the Erg11. The two A. fumigatus isolates were susceptible to MCF (MEC $=0.06 \mathrm{mg} / \mathrm{L})$. These isolates showed high fluconazole MIC value ( $>64 \mathrm{mg} / \mathrm{L})$, and low MIC values for VRC $(0.25 \mathrm{mg} / \mathrm{L})$, ITR $(0.5 \mathrm{mg} / \mathrm{L}), \operatorname{POS}(0.03 \mathrm{mg} / \mathrm{L})$, and ISA $(0.125 \mathrm{mg} / \mathrm{L})$. Both A. fumigatus isolates presented a WT cyp51A genotype, including its promoter.

\subsection{Relatedness of the Clinical Isolates}

Multilocus sequence typing (MLST), which defines strains as sequence types (STs) based on comparing the sequences at seven house-keeping loci and is the method of choice for molecular typing of many microorganisms, was used for the analysis of the population structure of 17 clinical isolates of $C$. albicans. We determined the presence of 15 different STs. Only two pairs of isolates-MB047 and M096, MB044 and MB059showed the same STs (Table 3). The relatedness of the C. albicans isolates is shown in the dendrogram (Figure 1). All 17 isolates clustered below the clade-defining limit of p-distance $<0.04$. Pulsed-field gel electrophoresis (PFGE)-based karyotyping, which separates whole chromosomes, revealed that $C$. albicans genome organization did not vary significantly among the different isolates recovered from the COVID-19 patients as compared to the reference strain SC5314 (Figure 2). TRESPERG typing performed for the A. fumigatus isolates showed different genotypes for the four genetic markers tested-isolate MB097 (t04A, m1.1, c13, e07), isolate MB098 (t04A, m3.5, c13, e07).

Table 3. Results of multilocus sequence typing (MLST) of Candida albicans isolates.

\begin{tabular}{|c|c|c|c|c|c|c|c|c|c|}
\hline Isolate & Specimen & $A A T 1 a$ & $A C C 1$ & $A D P 1$ & $M P I$ & SYA1 & VPS13 & ZWF1b & ST \\
\hline MB004 & Blood & 43 & 14 & 8 & 4 & 7 & 10 & 8 & 927 \\
\hline MB013 & Blood & 117 & 7 & 21 & 34 & * 238 & 24 & 6 & New ST, A \\
\hline MB026 & Blood & 25 & 7 & 6 & 3 & 6 & 27 & 37 & 90 \\
\hline МВ030 & Blood & 20 & 3 & 6 & 2 & 51 & 132 & 5 & New ST, B \\
\hline MB044 & Sputum & 2 & 5 & 5 & 2 & 2 & 6 & 20 & 485 \\
\hline MB047 & Sputum & 8 & 5 & $* 6$ & 2 & 2 & 6 & 5 & New ST, C \\
\hline MB056 & Sputum & 33 & 14 & 38 & 2 & * 136 & 122 & 15 & New ST, D \\
\hline MB059 & Sputum & 2 & 5 & 5 & 2 & 2 & 6 & 20 & 485 \\
\hline MB060 & Sputum & 8 & 3 & 6 & 2 & 2 & 6 & 49 & New ST, E \\
\hline MB064 & Sputum & 13 & 7 & 15 & 6 & 7 & 55 & 15 & 1830 \\
\hline MB092 & Blood & 33 & 7 & 6 & 2 & 78 & 122 & 15 & New ST, F \\
\hline MB096 & Blood & 8 & 5 & $* 6$ & 2 & 2 & 6 & 5 & New ST, C \\
\hline MB114 & Blood & 13 & 10 & 15 & 6 & 7 & 15 & 15 & New ST, G \\
\hline MB167 & Blood & 2 & 2 & 5 & 2 & 2 & 68 & 5 & New ST, H \\
\hline MB168 & Blood & 33 & 3 & 38 & 2 & 78 & 122 & 22 & New ST, I \\
\hline MB179 & Sputum & 8 & 2 & 5 & 9 & 2 & 6 & 5 & 285 \\
\hline MB180 & Sputum & 2 & 3 & 5 & 2 & 2 & 6 & 5 & 66 \\
\hline
\end{tabular}




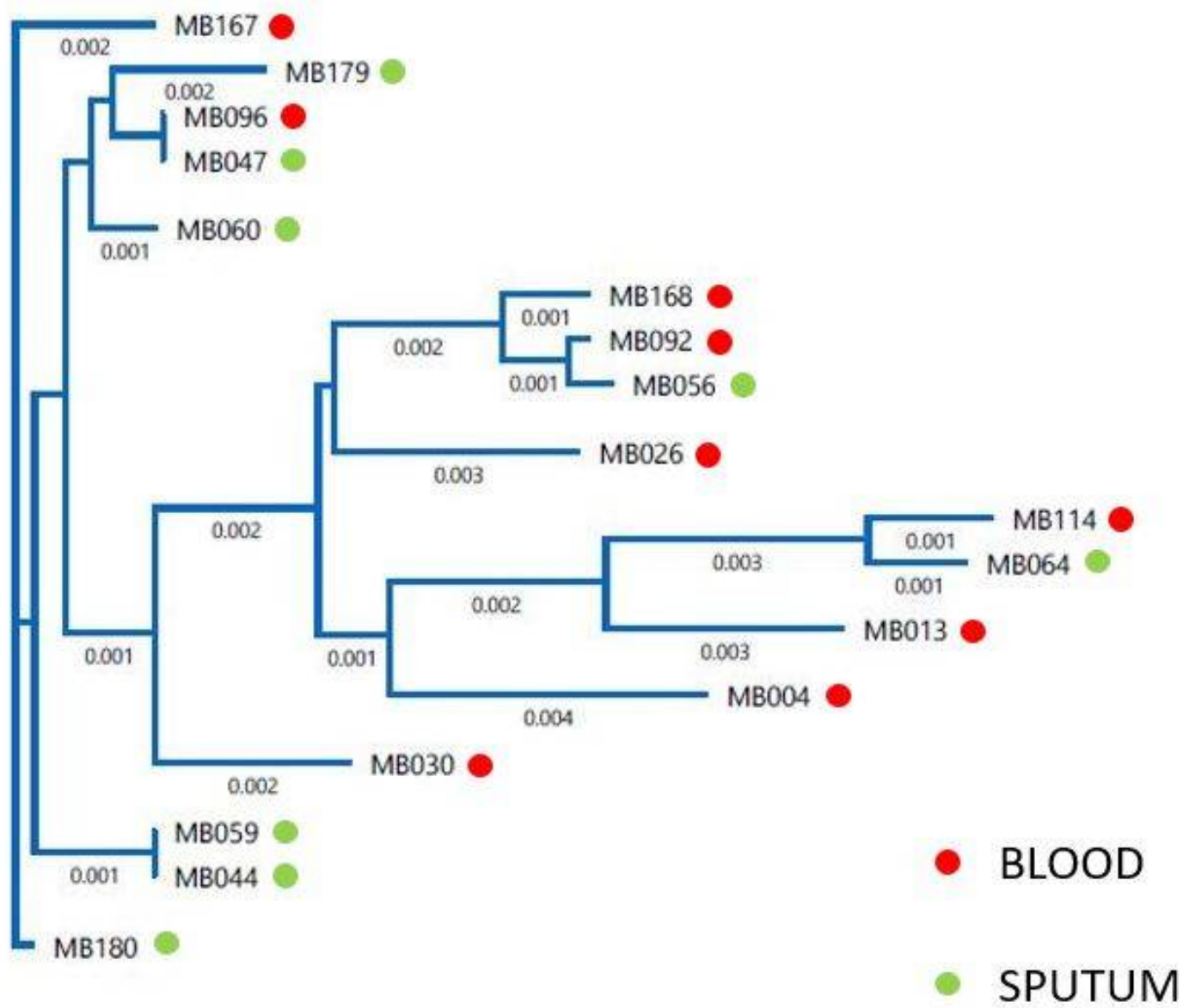

0.01

Figure 1. MLST-based dendrogram of 17 C. albicans clinical isolates (MB004-MB180) recovered from blood and sputum of COVID-19 patients.

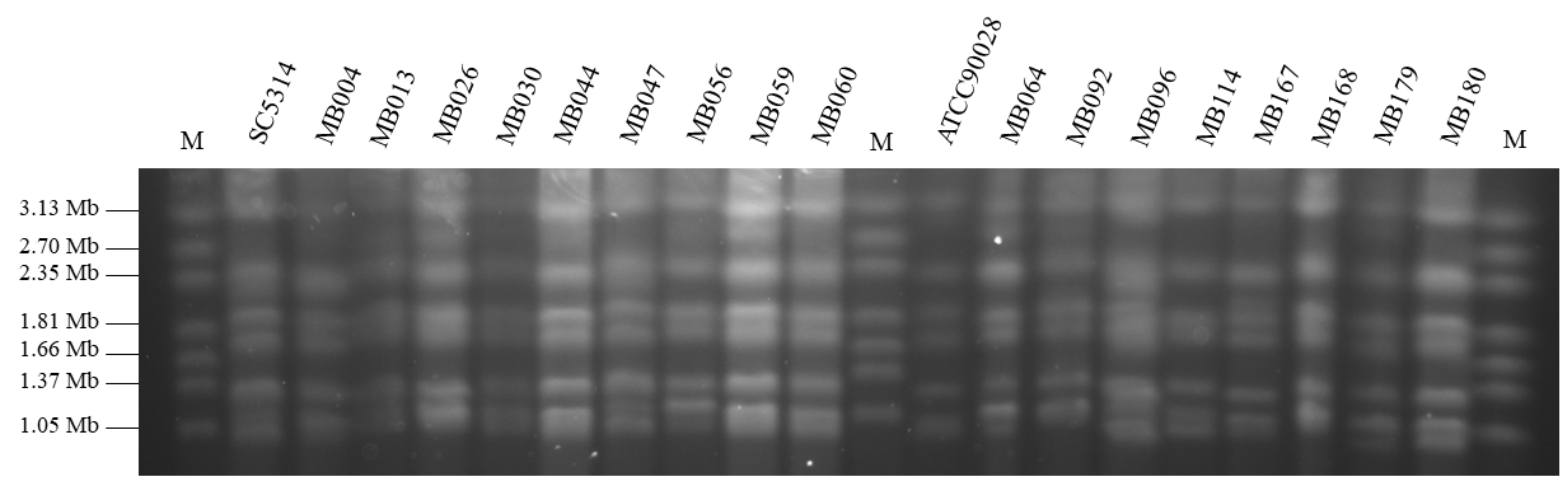

Figure 2. PFGE karyotypes of 17 Candida albicans clinical isolates (MB004-MB180) recovered from blood and sputum of COVID-19 patients. M: DNA Size Standard, Hansenula wingei; SC5314 \& ATCC90028_Candida albicans reference strains.

\subsection{Clinical Data Review}

The results of the clinical data review are presented in Table 4 (Summary of patient characteristics) and Table S1 (Clinical data for each patient). The two pairs of C. albicans isolates with the same STs (MB044 and MB059; MB047 and MB096) were recovered from the same patient. The median age of the patients was 60 years, and most of them $(68.4 \%)$ were of the male sex. The most common comorbidities were hypertension $(63.2 \%)$ and dia- 
betes (36.8\%). All patients (no information for one patient) were ventilated with a median duration of ventilation of 24 days. All patients received antibiotics, $63.2 \%$ received antifungals, $94.7 \%$ received corticosteroids, and $73.7 \%$ received hydroxychloroquine. Antifungal treatment was administered to 6/8 patients with fungal-positive blood culture (MB004; MB030, MB092; MB114; MB167; MB168), 3/3 patients with fungal-positive blood and sputum culture (MB026; MB047 \& MB096; MB099), and 3/8 patients with fungal-positive sputum culture (MB056; MB064; MB097). The median day from hospital admission to fungal culture was 14 and 12 for blood and sputum, respectively. The 30-day mortality in this population was $89.5 \%$. The only two of 19 patients that survived had C. albicans recovered from sputum and did not receive any antifungal drugs. According to the GarciaVidal criteria [9], only one patient's infection (MB098-A. fumigatus) would have been categorized as community-acquired.

Table 4. The main characteristics of patients whose fungal isolates were recovered from data and are shown as median (IQR) [range] or $n(\%)$.

\begin{tabular}{|c|c|}
\hline Characteristic & Values \\
\hline Age & $60(55-69)(49-84)$ \\
\hline BMI & $29.3(24.96-37.34)(22.91-58.5)$ \\
\hline$\geq 30$ & $8(42.1 \%)$ \\
\hline \multicolumn{2}{|l|}{ Sex } \\
\hline Male & $13(68.4 \%)$ \\
\hline Female & $6(31.6 \%)$ \\
\hline \multicolumn{2}{|l|}{ Comorbidities } \\
\hline Diabetes & $7(36.8 \%)$ \\
\hline Asthma & $3(15.8 \%)$ \\
\hline COPD & $1(5.3 \%)$ \\
\hline Hypertension & $12(63.2 \%)$ \\
\hline Cancer & 0 \\
\hline Hypercholesterolemia & $5(26.3 \%)$ \\
\hline Hyperlipidemia & $2(10.5 \%)$ \\
\hline Arthritis & $4(21.1 \%)$ \\
\hline \multicolumn{2}{|l|}{ Treatment } \\
\hline Antibiotics & $19(100 \%)$ \\
\hline Antifungals & $12(63.2 \%)$ \\
\hline Corticosteroids & $18(94.7 \%)$ \\
\hline Hydroxychloroquine & $14(73.7 \%)$ \\
\hline Remdesivir & $3(15.8 \%)$ \\
\hline Lopinavir-ritonavir & $1(5.3 \%)$ \\
\hline Sarilumab & $1(5.3 \%)$ \\
\hline \multicolumn{2}{|l|}{ Fungal culture } \\
\hline Day of the first blood culture & $14(11-19)(8-28)$ \\
\hline Day of the first sputum culture & $12(6-18)(1-40)$ \\
\hline Fungal culture only & $6(31.6 \%)$ \\
\hline Fungal and bacterial culture & $13(68.4 \%)$ \\
\hline \multicolumn{2}{|l|}{ Hospitalization } \\
\hline Days of hospital stay & $29(15-33)(9-81)$ \\
\hline ICU admission & $6(31.6 \%)$ \\
\hline Days in ICU & $24(8.25-41.25)(0-54)$ \\
\hline Ventilation & $18(94.7 \%)$ * \\
\hline Days on ventilator & $24(11-31.25)(7-81)$ \\
\hline Death & $17(89.5 \%)$ \\
\hline Respiratory failure & $14 / 17(82.3 \%)$ \\
\hline Cardiac failure & $2 / 17(11.8 \%)$ \\
\hline No data & $1 / 17(5.9 \%)$ \\
\hline
\end{tabular}

\footnotetext{
* no data available for one patient.
} 


\section{Discussion}

A scatter of preliminary studies indicates that secondary bacterial and fungal infections are present in up to $58 \%$ of hospitalized patients with severe COVID-19 [7,9,36]. COVID-19associated pulmonary aspergillosis (CAPA) and COVID-19-associated candidiasis (CAC) were recorded in many countries with reported incidence from $4-35 \%$ and $0.7-12.6 \%$, respectively [9,37-40]. However, in most healthcare settings a somewhat unique diagnostic challenge arose in assessing and managing secondary infections in this population relative to other respiratory viral illnesses. In order to minimize aerosol-generating procedures and healthcare workers' exposure, most healthcare facilities avoided invasive diagnostic procedures such as bronchoscopy, bronchoalveolar lavage or bronchial wash, and radiologic imaging such as computed tomography (CT) [41]. With such limited diagnostic options, prohibited autopsies, and a lack of definitions for COVID-19-associated secondary diseases in the early days of the pandemic, the true prevalence of secondary fungal infections in the COVID-19 patient population remains unclear.

Here, we based our study on available microbiological material -21 fungal isolates that were recovered from cultures of sputum and blood of 19 severely ill COVID-19 patients at the Department of Pathology at Hackensack University Medical Center (HUMC) in Hackensack, New Jersey, USA. Eleven yeast isolates recovered from blood were identified to the species level as C. albicans (9 isolates) and C. parapsilosis ( 2 isolates). Among 10 fungal isolates recovered from sputum, mold isolates were identified as A. fumigatus. The remaining 8 yeast isolates were only labeled as "yeast", or "yeast, not Cryptococcus". It is common that laboratories in the United States do not perform species identification of yeast isolates, especially the non-invasive ones [42]. Ultimately, all these isolates were identified as $C$. albicans by molecular methods. It is noteworthy that $C$. auris was not identified in any of our patients, despite its outbreak status in the State.

Candida spp. are isolated from respiratory tract specimens relatively often, especially those obtained from patients on mechanical ventilation. However, the differentiation between colonization and infection is very complicated given no specific diagnostic criteria for ventilator-associated pneumonia exist [43]. It is recommended that Candida pneumonia is diagnosed by histopathology [43], which due to the primary disease (COVID-19), was not performed in any of the patients included in the study.

It has been recently speculated that microbiology and antifungal drug resistance patterns will likely be consistent with institutional ecology [15]. Several studies assessed the susceptibility of fungal isolates recovered from COVID-19 patients. Not surprisingly, all C. auris isolates were found to be resistant to at least one drug [40,44], whereas no antifungal drug resistance was observed in the majority of isolates from other Candida species (C. albicans, C. glabrata, C. tropicalis) [40,45,46] and Saccharomyces cerevisiae [47]. Single cases of fatal infections caused by drug-resistant $C$. glabrata and A. fumigatus were reported in Italy [13] and in the Netherlands [48], respectively.

Hospitals throughout the US have long been struggling to control the use of antibiotics and the many unknowns of COVID-19 have created additional challenges for antimicrobial stewardship programs [49]. Guidelines recommend empirical antibiotics for all patients who are severely ill with suspected COVID-19, and that cessation of therapy is left to the clinicians' discretion [50]. Not surprisingly, reports to date indicate that antibiotic use is very high (75-100\%) among severely ill COVID-19 patients [51-54]. Moreover, one study from China reported that $7.5 \%$ of patients with severe COVID-19 were treated with antifungals [52], while in one hospital in Valencia (Spain), antifungal consumption increased by $15 \%$ and $75 \%$ in the entire hospital and ICU, respectively [44].

All tested yeast isolates (C. albicans and C. parapsilosis) presented low echinocandin (MCF) MIC values (categorized as susceptible according to the CLSI breakpoints) and a WT FKS1 genotype. They also had low azole MIC values (categorized as susceptible according to the CLSI breakpoints for FLC and VRC). Among 10 different ERG11 genotypes found in C. albicans, none of the resulting Erg11 amino acid changes is associated with azole resistance [55-58]. The amino acid change F215S in Erg11 of C. parapsilosis 
has not been described before but given the low azole MIC values of these isolates, most likely it has no impact on azole susceptibility. The two A. fumigatus isolates had MCF MEC of $0.06 \mathrm{mg} / \mathrm{L}$. Given that neither CLSI nor the European Committee on Antimicrobial Susceptibility Testing (EUCAST) provides any recommendation of interpretation for A. fumigatus susceptibility testing results with echinocandins (no breakpoints due to the lack of correlation between MEC and outcomes), the available epidemiological cutoff value $(\mathrm{ECV} \leq 0.06 \mathrm{mg} / \mathrm{L})[59,60]$ was applied and isolates were categorized as susceptible. A. fumigatus isolates had a high fluconazole MIC value $(>64 \mathrm{mg} / \mathrm{L})$ since this species is intrinsically resistant to this compound [61], and low MIC values for VRC (0.25 mg/L), ITR $(0.5 \mathrm{mg} / \mathrm{L})$, POS (0.03 mg/L), and ISA $(0.125 \mathrm{mg} / \mathrm{L})$. All A. fumigatus isolates presented a WT CYP51A genotype and promoter which agrees with the susceptibility results obtained.

In summary, all 21 fungal isolates were fully susceptible to echinocandin and azole drugs. However, we were not able to assess whether any of the isolates developed antifungal drug resistance during the antifungal treatment (63.2\% of patients received antifungals) since no sequential isolates were collected. Moreover, it is unknown if such a susceptibility pattern is characteristic for this health center since no susceptibility data were available for isolates collected in years preceding the pandemic.

Molecular typing can help understand multiple aspects of infectious disease, including pathogen dynamics in a given population, the source/origin of infection, and the relatedness of isolates of the same species [62]. Here, we applied a highly discriminatory and standardized MLST approach for analysis of the population structure of C. albicans isolates. We discovered the presence of 15 sequence types (STs), of which 9 were not identified before. Only 3 STs-66, 90, and 485 were previously detected in the US (according to the PubMLST.org database). Identical STs were only obtained when isolates were recovered from different specimens of the same patient. Subsequent concatenation of generated MLST sequences revealed that all 17 C. albicans isolates belonged to one cluster (clustered below the clade-defining limit of p-distance $<0.04$ ). Further studies are needed to determine the prevalence of detected STs among C. albicans strains infecting HUMC patients and in the general New Jersey population. The karyotypes (the number and size of chromosomes) of the 17 C. albicans isolates recovered from the COVID-19 patients revealed no chromosomal rearrangements (copy number variation, loss of heterozygosity, translocations, chromosome truncations) that may occur in response to stresses such as heat shock, host-pathogen interactions including host immunologic responses, and the presence of antifungal drugs [63-65]. Since no sequential isolates were collected from the patients, it was not possible to determine if the antifungal therapy provoked changes in the genetic diversity. Collectively, performed typing (MLST and karyotyping) revealed that C. albicans isolates recovered from COVID-19 patients were closely related but no clonal spread occurred at HUMC. Analysis of TRESPERG typing results revealed that both A. fumigatus isolates were different and non-related based on the genotyping methodology used which was expected as they were isolated from different patients. Since A. fumigatus TRESPERG typing is relatively new and has not been broadly implemented in the clinical setting, the determined TRESPERG profiles have never been described before $[32,66]$. Performed analysis of Candida and Aspergillus isolates recovered from COVID-19 patients provides new and useful information in the clinical context since it confirms that there was no outbreak of infection or colonization observed in the studied patient population.

Hospitalized patients, critically ill with COVID-19 are at high risk for the development of secondary infections due to the systemic nature, mechanical ventilation, and prolonged hospital and ICU stays associated with severe primary disease. We speculate that these factors played a role in our patient population since the median duration of hospital stay was 29 days (range: 9-81 days) and all patients (no information for one patient) were ventilated with a median duration of ventilation of 24 days (range: 7-81 days). Moreover, COVID-19 patients experience major lung damage (due to viral replication) and immune dysregulation, which is modulated by the use of corticosteroids, anti-IL-6 monoclonal antibodies (tocilizumab, sarilumab), or other immunomodulatory agents [15]. Here, 94.7\% of 
the patients received corticosteroids. Additionally, one patient received sarilumab. A combination of virus- and drug-induced immunosuppression likely increased the susceptibility to secondary infections. The 30-day mortality in this population was $89.5 \%$, which is higher than the overall reported mortality of $68.5 \%(217 / 317)$ from ventilated patients at HUMC in the comparable time period [67]. The elevated mortality rate in COVID-19 patients with fungal superinfections, irrespective of the drug resistance profile of the infecting organism, is in agreement with other reports on COVID-19-associated candidemia [11,12,68].

We recognize several limitations of our study, in which we analyzed only a small number of fungal isolates $(n=21)$ due to the research restrictions implemented at HUMC in the initial phase of the COVID-19 pandemic (April-May 2020). Given the diagnostic restrictions, we cannot exclude that one of the recovered Aspergillus isolates (MB098) represented environmental contamination rather than a causative agent of infection. Similarly, despite the assumption that all the sputum samples represent lower respiratory tract flora rather than flora in the mouth (all patients were ventilated, and sputum samples were collected through suction) but lacking histopathology data, we do not have a definite clinical implication for C. albicans presence in the sputum samples. However, the presence of fungi in blood or respiratory tract fluid was an indicator of the patient's severe condition and a prognosticator for poor clinical outcome, which presented as an $89.5 \% 30$-day mortality in our patient cohort. Such observation is consistent with the results of a study performed in Brazil, where mechanically-ventilated patients with positive cultures were 3.8 times more likely to die than those without superinfections [69]. Lastly, we were not able to assess whether any of the isolates developed antifungal drug resistance during the antifungal treatment and whether the susceptibility pattern is characteristic for this health center. Given the existing data on the high mortality of COVID-19-associated secondary infections, preparing for the prevention, diagnosis, and treatment of these infections is an important adjunct to addressing COVID-19 and related respiratory viral diseases such as influenza.

Supplementary Materials: The following are available online at https:/ /www.mdpi.com/article/10 .3390/jof7070552/s1, Table S1: Clinical data for each patient.

Author Contributions: Conceptualization, M.K., B.N.K. and D.S.P.; methodology, M.K., R.G.-R. and C.J.-O.; formal analysis, M.K.; investigation, K.D.G., R.G.-R., C.J.-O., M.K.; resources, J.R.M., M.H.C., F.H., T.H.; data curation, J.R.M., M.H.C. and K.F.C.; writing-original draft preparation, M.K., R.G.-R. and C.J.-O.; writing-review and editing, M.K., K.D.G., R.G.-R., C.J.-O., J.R.M., M.H.C., F.H., T.H., K.F.C., B.N.K., D.S.P.; visualization, M.K. and C.J.-O.; supervision, M.K., B.N.K. and D.S.P.; project administration, M.K., B.N.K. and D.S.P.; funding acquisition, M.K., B.N.K. and D.S.P. All authors have read and agreed to the published version of the manuscript.

Funding: This work was supported by Merck's Investigator Studies Program (MISP) SARS CoV2/COVID-19 award MISP 60453 to B.N.K. and M.K. ("Drug resistance profiles of bacterial and fungal isolates from super-infections in hospitalized COVID-19 patients"), CDI COVID-19 Pilot Research Grant to M.K., CDI COVID-19 Response, and HMH Foundation.

Institutional Review Board Statement: The study was conducted according to the guidelines of the Declaration of Helsinki, and received Hackensack University Medical Center Institutional Review Board approval (Study ID: Pro2018-1022 approved on 19 February 2019).

Informed Consent Statement: Not applicable.

Data Availability Statement: All data are available within the article and Supplementary Materials.

Conflicts of Interest: D.S.P. receives funding from the U.S. National Institutes of Health and contracts with Merck, Regeneron and Pfizer. He serves on advisory boards for Amplyx, Astellas, Cidara, Matinas, N8 Medical and Scynexis. In addition, D.S.P. has an issued U.S. patent concerning echinocandin resistance and fungal detection. The remaining authors declare that the research was conducted in the absence of any commercial or financial relationships that could be construed as a potential conflict of interest. The funders had no role in the design of the study; in the collection, analyses, or interpretation of data; in the writing of the manuscript, or in the decision to publish the results. D.S.P. has recused himself as Editor-in-Chief from any decision regarding this manuscript. 


\section{References}

1. WHO. WHO Coronavirus Disease (COVID-19) Dashboard. Available online: https:/ / covid19.who.int/ (accessed on 6 May 2021).

2. Liderot, K.; Ahl, M.; Ozenci, V. Secondary bacterial infections in patients with seasonal influenza A and pandemic H1N1. BioMed Res. Int. 2013, 2013, 376219. [CrossRef] [PubMed]

3. Rijnders, B.J.A.; Schauwvlieghe, A.; Wauters, J. Influenza-associated pulmonary aspergillosis: A local or global lethal combination? Clin. Infect. Dis. 2020, 71, 1764-1767. [CrossRef]

4. Zheng, Z.G.; Chen, R.C.; Li, Y.M. The clinical characteristics of secondary infection of lower respiratory in severe acute respiratory syndrome. Chin. J. Respir. Crit. Care Med. 2003, 2, 270-274.

5. Hwang, D.M.; Chamberlain, D.W.; Poutanen, S.M.; Low, D.E.; Asa, S.L.; Butany, J. Pulmonary pathology of severe acute respiratory syndrome in Toronto. Mod. Pathol. 2005, 18, 1-10. [CrossRef] [PubMed]

6. Wu, Y.P.; Wei, R.; Verhoef, J. Real time assay of Aspergillus should be used in SARS patients receiving corticosteroids. BMJ 2003, 327, 1405. [CrossRef] [PubMed]

7. Zhou, F.; Yu, T.; Du, R.; Fan, G.; Liu, Y.; Liu, Z.; Xiang, J.; Wang, Y.; Song, B.; Gu, X.; et al. Clinical course and risk factors for mortality of adult inpatients with COVID-19 in Wuhan, China: A retrospective cohort study. Lancet 2020, 395, $1054-1062$. [CrossRef]

8. Goyal, P.; Choi, J.J.; Pinheiro, L.C.; Schenck, E.J.; Chen, R.; Jabri, A.; Satlin, M.J.; Campion, T.R., Jr.; Nahid, M.; Ringel, J.B.; et al. Clinical Characteristics of Covid-19 in New York City. N. Engl. J. Med. 2020, 382, 2372-2374. [CrossRef] [PubMed]

9. Garcia-Vidal, C.; Sanjuan, G.; Moreno-Garcia, E.; Puerta-Alcalde, P.; Garcia-Pouton, N.; Chumbita, M.; Fernandez-Pittol, M.; Pitart, C.; Inciarte, A.; Bodro, M.; et al. Incidence of co-infections and superinfections in hospitalized patients with COVID-19: A retrospective cohort study. Clin. Microbiol. Infect. 2020, 27, 83-88. [CrossRef] [PubMed]

10. Nucci, M.; Barreiros, G.; Guimaraes, L.F.; Deriquehem, V.A.S.; Castineiras, A.C.; Nouer, S.A. Increased incidence of candidemia in a tertiary care hospital with the COVID-19 pandemic. Mycoses 2021, 64, 152-156. [CrossRef]

11. Mastrangelo, A.; Germinario, B.N.; Ferrante, M.; Frangi, C.; Li Voti, R.; Muccini, C.; Ripa, M.; COVID-BioB Study Group. Candidemia in COVID-19 patients: Incidence and characteristics in a prospective cohort compared to historical non-COVID-19 controls. Clin. Infect. Dis. 2020, ciaa1594. [CrossRef] [PubMed]

12. Villanueva-Lozano, H.; Trevino-Rangel, R.J.; Gonzalez, G.M.; Ramirez-Elizondo, M.T.; Lara-Medrano, R.; Aleman-Bocanegra, M.C.; Guajardo-Lara, C.E.; Gaona-Chavez, N.; Castilleja-Leal, F.; Torre-Amione, G.; et al. Outbreak of Candida auris infection in a COVID-19 hospital in Mexico. Clin. Microbiol. Infect. 2021, 27, 813-816. [CrossRef]

13. Posteraro, B.; Torelli, R.; Vella, A.; Leone, P.M.; De Angelis, G.; De Carolis, E.; Ventura, G.; Sanguinetti, M.; Fantoni, M. PanEchinocandin-Resistant Candida glabrata Bloodstream Infection Complicating COVID-19: A Fatal Case Report. J. Fungi 2020, 6, 163. [CrossRef] [PubMed]

14. Alanio, A.; Delliere, S.; Fodil, S.; Bretagne, S.; Megarbane, B. Prevalence of putative invasive pulmonary aspergillosis in critically ill patients with COVID-19. Lancet Respir. Med. 2020, 8, e48-e49. [CrossRef]

15. Clancy, C.J.; Nguyen, M.H. COVID-19, superinfections and antimicrobial development: What can we expect? Clin. Infect. Dis. 2020, 71, 2736-2743. [CrossRef] [PubMed]

16. Chen, G.; Wu, D.; Guo, W.; Cao, Y.; Huang, D.; Wang, H.; Wang, T.; Zhang, X.; Chen, H.; Yu, H.; et al. Clinical and immunological features of severe and moderate coronavirus disease 2019. J. Clin. Investig. 2020, 130, 2620-2629. [CrossRef]

17. Huang, C.; Wang, Y.; Li, X.; Ren, L.; Zhao, J.; Hu, Y.; Zhang, L.; Fan, G.; Xu, J.; Gu, X.; et al. Clinical features of patients infected with 2019 novel coronavirus in Wuhan, China. Lancet 2020, 395, 497-506. [CrossRef]

18. Yang, X.; Yu, Y.; Xu, J.; Shu, H.; Xia, J.; Liu, H.; Wu, Y.; Zhang, L.; Yu, Z.; Fang, M.; et al. Clinical course and outcomes of critically ill patients with SARS-CoV-2 pneumonia in Wuhan, China: A single-centered, retrospective, observational study. Lancet Respir. Med. 2020, 8, 475-481. [CrossRef]

19. Du, Y.; Tu, L.; Zhu, P.; Mu, M.; Wang, R.; Yang, P.; Wang, X.; Hu, C.; Ping, R.; Hu, P.; et al. Clinical Features of 85 Fatal Cases of COVID-19 from Wuhan. A Retrospective Observational Study. Am. J. Respir. Crit. Care Med. 2020, 201, 1372-1379. [CrossRef] [PubMed]

20. Arentz, M.; Yim, E.; Klaff, L.; Lokhandwala, S.; Riedo, F.X.; Chong, M.; Lee, M. Characteristics and Outcomes of 21 Critically Ill Patients With COVID-19 in Washington State. JAMA 2020, 323, 1612-1614. [CrossRef] [PubMed]

21. Wang, D.; Hu, B.; Hu, C.; Zhu, F.; Liu, X.; Zhang, J.; Wang, B.; Xiang, H.; Cheng, Z.; Xiong, Y.; et al. Clinical Characteristics of 138 Hospitalized Patients With 2019 Novel Coronavirus-Infected Pneumonia in Wuhan, China. JAMA 2020, 323, $1061-1069$. [CrossRef] [PubMed]

22. Grasselli, G.; Zangrillo, A.; Zanella, A.; Antonelli, M.; Cabrini, L.; Castelli, A.; Cereda, D.; Coluccello, A.; Foti, G.; Fumagalli, R.; et al. Baseline Characteristics and Outcomes of 1591 Patients Infected With SARS-CoV-2 Admitted to ICUs of the Lombardy Region, Italy. JAMA 2020, 323, 1574-1581. [CrossRef]

23. Brillowska-Dabrowska, A.; Nielsen, S.S.; Nielsen, H.V.; Arendrup, M.C. Optimized 5-hour multiplex PCR test for the detection of tinea unguium: Performance in a routine PCR laboratory. Med. Mycol. 2010, 48, 828-831. [CrossRef] [PubMed]

24. CLSI. Reference Method for Broth Dilution Antifungal Susceptibility Testing of Yeast. In CLSI Standard M27, 4th ed.; Clinical and Laboratory Standards Institute: Wayne, PA, USA, 2017.

25. CLSI. Performance Standards for Antifungal Susceptibility Testing of Yeasts. In CLSI Supplement M60, 2nd ed.; Clinical and Laboratory Standards Institute: Wayne, PA, USA, 2020. 
26. CLSI. Reference Method for Broth Dilution Antifungal Susceptibility Testing of Filamentous Fungi. In CLSI Standard M38, 3rd ed.; Clinical and Laboratory Standards Institute: Wayne, PA, USA, 2017.

27. CLSI. Performance Standards for Antifungal Susceptibility Testing of Filamentous Fungi. In CLSI Supplement M61, 2nd ed.; Clinical and Laboratory Standards Institute: Wayne, PA, USA, 2020.

28. Mellado, E.; Garcia-Effron, G.; Alcazar-Fuoli, L.; Melchers, W.J.; Verweij, P.E.; Cuenca-Estrella, M.; Rodriguez-Tudela, J.L. A new Aspergillus fumigatus resistance mechanism conferring in vitro cross-resistance to azole antifungals involves a combination of cyp51A alterations. Antimicrob. Agents Chemother. 2007, 51, 1897-1904. [CrossRef] [PubMed]

29. Bai, F.Y.; Liang, H.Y.; Jia, J.H. Taxonomic relationships among the taxa in the Candida guilliermondii complex, as revealed by comparative electrophoretic karyotyping. Int. J. Syst. Evol. Microbiol. 2000, 50, 417-422. [CrossRef] [PubMed]

30. Bougnoux, M.E.; Tavanti, A.; Bouchier, C.; Gow, N.A.; Magnier, A.; Davidson, A.D.; Maiden, M.C.; D’Enfert, C.; Odds, F.C. Collaborative consensus for optimized multilocus sequence typing of Candida albicans. J. Clin. Microbiol. 2003, 41, 5265-5266. [CrossRef]

31. Odds, F.C.; Bougnoux, M.E.; Shaw, D.J.; Bain, J.M.; Davidson, A.D.; Diogo, D.; Jacobsen, M.D.; Lecomte, M.; Li, S.Y.; Tavanti, A.; et al. Molecular phylogenetics of Candida albicans. Eukaryot. Cell 2007, 6, 1041-1052. [CrossRef] [PubMed]

32. Garcia-Rubio, R.; Escribano, P.; Gomez, A.; Guinea, J.; Mellado, E. Comparison of Two Highly Discriminatory Typing Methods to Analyze Aspergillus fumigatus Azole Resistance. Front. Microbiol. 2018, 9, 1626. [CrossRef] [PubMed]

33. Alcazar-Fuoli, L.; Mellado, E.; Alastruey-Izquierdo, A.; Cuenca-Estrella, M.; Rodriguez-Tudela, J.L. Aspergillus section Fumigati: Antifungal susceptibility patterns and sequence-based identification. Antimicrob. Agents Chemother. 2008, 52, 1244-1251. [CrossRef] [PubMed]

34. Arendrup, M.C.; Garcia-Effron, G.; Lass-Florl, C.; Lopez, A.G.; Rodriguez-Tudela, J.L.; Cuenca-Estrella, M.; Perlin, D.S. Echinocandin susceptibility testing of Candida species: Comparison of EUCAST EDef 7.1, CLSI M27-A3, Etest, disk diffusion, and agar dilution methods with RPMI and isosensitest media. Antimicrob. Agents Chemother. 2010, 54, 426-439. [CrossRef] [PubMed]

35. Garcia-Effron, G.; Katiyar, S.K.; Park, S.; Edlind, T.D.; Perlin, D.S. A naturally occurring proline-to-alanine amino acid change in Fks1p in Candida parapsilosis, Candida orthopsilosis, and Candida metapsilosis accounts for reduced echinocandin susceptibility. Antimicrob. Agents. Chemother. 2008, 52, 2305-2312. [CrossRef]

36. Zhang, H.; Zhang, Y.; Wu, J.; Li, Y.; Zhou, X.; Li, X.; Chen, H.; Guo, M.; Chen, S.; Sun, F.; et al. Risks and features of secondary infections in severe and critical ill COVID-19 patients. Emerg. Microbes Infect. 2020, 9, 1958-1964. [CrossRef]

37. Lamoth, F.; Glampedakis, E.; Boillat-Blanco, N.; Oddo, M.; Pagani, J.L. Incidence of invasive pulmonary aspergillosis among critically ill COVID-19 patients. Clin. Microbiol. Infect. 2020, 26, 1706-1708. [CrossRef] [PubMed]

38. Rutsaert, L.; Steinfort, N.; Van Hunsel, T.; Bomans, P.; Naesens, R.; Mertes, H.; Dits, H.; Van Regenmortel, N. COVID-19-associated invasive pulmonary aspergillosis. Ann. Intensive Care 2020, 10, 71. [CrossRef] [PubMed]

39. White, P.L.; Dhillon, R.; Cordey, A.; Hughes, H.; Faggian, F.; Soni, S.; Pandey, M.; Whitaker, H.; May, A.; Morgan, M.; et al. A national strategy to diagnose COVID-19 associated invasive fungal disease in the ICU. Clin. Infect. Dis. 2020, ciaa1298. [CrossRef] [PubMed]

40. Chowdhary, A.; Tarai, B.; Singh, A.; Sharma, A. Multidrug-Resistant Candida auris Infections in Critically Ill Coronavirus Disease Patients, India, April-July 2020. Emerg. Infect. Dis. 2020, 26, 2694-2696. [CrossRef] [PubMed]

41. Peman, J.; Ruiz-Gaitan, A.; Garcia-Vidal, C.; Salavert, M.; Ramirez, P.; Puchades, F.; Garcia-Hita, M.; Alastruey-Izquierdo, A.; Quindos, G. Fungal co-infection in COVID-19 patients: Should we be concerned? Rev. Iberoam. Micol. 2020, 37, 41-46. [CrossRef] [PubMed]

42. Lockhart, S.R.; Jackson, B.R.; Vallabhaneni, S.; Ostrosky-Zeichner, L.; Pappas, P.G.; Chiller, T. Thinking beyond the Common Candida Species: Need for Species-Level Identification of Candida Due to the Emergence of Multidrug-Resistant Candida auris. J. Clin. Microbiol. 2017, 55, 3324-3327. [CrossRef]

43. Liu, J.; Yu, Y.T.; Xu, C.H.; Chen, D.C. Candida Colonization in the Respiratory Tract: What Is the Significance? Front. Med. 2020, 7, 598037. [CrossRef] [PubMed]

44. Mulet Bayona, J.V.; Tormo Palop, N.; Salvador Garcia, C.; Fuster Escriva, B.; Chanza Avino, M.; Ortega Garcia, P.; Gimeno Cardona, C. Impact of the SARS-CoV-2 Pandemic in Candidaemia, Invasive Aspergillosis and Antifungal Consumption in a Tertiary Hospital. J. Fungi 2021, 7, 440. [CrossRef] [PubMed]

45. Al-Hatmi, A.M.S.; Mohsin, J.; Al-Huraizi, A.; Khamis, F. COVID-19 associated invasive candidiasis. J. Infect. 2021, 82, e45-e46. [CrossRef] [PubMed]

46. Gorkem, A.; Sav, H.; Kaan, O.; Eren, E. Coronavirus disease and candidemia infection: A case report. J. Mycol. Med. 2021, 31, 101155. [CrossRef] [PubMed]

47. Ventoulis, I.; Sarmourli, T.; Amoiridou, P.; Mantzana, P.; Exindari, M.; Gioula, G.; Vyzantiadis, T.A. Bloodstream Infection by Saccharomyces cerevisiae in Two COVID-19 Patients after Receiving Supplementation of Saccharomyces in the ICU. J. Fungi 2020, 6, 98. [CrossRef] [PubMed]

48. Meijer, E.F.J.; Dofferhoff, A.S.M.; Hoiting, O.; Buil, J.B.; Meis, J.F. Azole-Resistant COVID-19-Associated Pulmonary Aspergillosis in an Immunocompetent Host: A Case Report. J. Fungi 2020, 6, 79. [CrossRef] [PubMed]

49. Martin, E.; Philbin, M.; Hughes, G.; Bergin, C.; Talento, A.F. Antimicrobial stewardship challenges and innovative initiatives in the acute hospital setting during the COVID-19 pandemic. J. Antimicrob. Chemother. 2021, 76, 272-275. [CrossRef] [PubMed] 
50. Adler, H.; Ball, R.; Fisher, M.; Mortimer, K.; Vardhan, M.S. Low rate of bacterial co-infection in patients with COVID-19. Lancet Microbe 2020, 1, e62. [CrossRef]

51. Chen, T.; Wu, D.; Chen, H.; Yan, W.; Yang, D.; Chen, G.; Ma, K.; Xu, D.; Yu, H.; Wang, H.; et al. Clinical characteristics of 113 deceased patients with coronavirus disease 2019: Retrospective study. BMJ 2020, 368, m1091. [CrossRef] [PubMed]

52. Guan, W.J.; Ni, Z.Y.; Hu, Y.; Liang, W.H.; Ou, C.Q.; He, J.X.; Liu, L.; Shan, H.; Lei, C.L.; Hui, D.S.C.; et al. Clinical Characteristics of Coronavirus Disease 2019 in China. N. Engl. J. Med. 2020, 382, 1708-1720. [CrossRef]

53. Cox, M.J.; Loman, N.; Bogaert, D.; O'Grady, J. Co-infections: Potentially lethal and unexplored in COVID-19. Lancet Microbe 2020, 1, e11. [CrossRef]

54. Zhou, P.; Liu, Z.; Chen, Y.; Xiao, Y.; Huang, X.; Fan, X.G. Bacterial and fungal infections in COVID-19 patients: A matter of concern. Infect. Control Hosp. Epidemiol. 2020, 41, 1124-1125. [CrossRef] [PubMed]

55. Perea, S.; Lopez-Ribot, J.L.; Kirkpatrick, W.R.; McAtee, R.K.; Santillan, R.A.; Martinez, M.; Calabrese, D.; Sanglard, D.; Patterson, T.F. Prevalence of molecular mechanisms of resistance to azole antifungal agents in Candida albicans strains displaying high-level fluconazole resistance isolated from human immunodeficiency virus-infected patients. Antimicrob. Agents Chemother. 2001, 45, 2676-2684. [CrossRef] [PubMed]

56. Flowers, S.A.; Colon, B.; Whaley, S.G.; Schuler, M.A.; Rogers, P.D. Contribution of clinically derived mutations in ERG11 to azole resistance in Candida albicans. Antimicrob. Agents Chemother. 2015, 59, 450-460. [CrossRef] [PubMed]

57. Ying, Y.; Zhao, Y.; Hu, X.; Cai, Z.; Liu, X.; Jin, G.; Zhang, J.; Zhang, J.; Liu, J.; Huang, X. In vitro fluconazole susceptibility of 1,903 clinical isolates of Candida albicans and the identification of ERG11 mutations. Microb. Drug Resist. 2013, 19, 266-273. [CrossRef] [PubMed]

58. Xu, Y.; Chen, L.; Li, C. Susceptibility of clinical isolates of Candida species to fluconazole and detection of Candida albicans ERG11 mutations. J. Antimicrob. Chemother. 2008, 61, 798-804. [CrossRef] [PubMed]

59. Pfaller, M.A.; Boyken, L.; Hollis, R.J.; Kroeger, J.; Messer, S.A.; Tendolkar, S.; Diekema, D.J. In vitro susceptibility of clinical isolates of Aspergillus spp. to anidulafungin, caspofungin, and micafungin: A head-to-head comparison using the CLSI M38-A2 broth microdilution method. J. Clin. Microbiol. 2009, 47, 3323-3325. [CrossRef] [PubMed]

60. Pfaller, M.A.; Boyken, L.; Hollis, R.J.; Kroeger, J.; Messer, S.A.; Tendolkar, S.; Diekema, D.J. Wild-type minimum effective concentration distributions and epidemiologic cutoff values for caspofungin and Aspergillus spp. as determined by Clinical and Laboratory Standards Institute broth microdilution methods. Diagn. Microbiol. Infect. Dis. 2010, 67, 56-60. [CrossRef] [PubMed]

61. Leonardelli, F.; Macedo, D.; Dudiuk, C.; Cabeza, M.S.; Gamarra, S.; Garcia-Effron, G. Aspergillus fumigatus Intrinsic Fluconazole Resistance Is Due to the Naturally Occurring T301I Substitution in Cyp51Ap. Antimicrob. Agents Chemother. 2016, 60, 5420-5426. [CrossRef]

62. McManus, B.A.; Coleman, D.C. Molecular epidemiology, phylogeny and evolution of Candida albicans. Infect. Genet. Evol. 2014, 21, 166-178. [CrossRef]

63. Selmecki, A.; Forche, A.; Berman, J. Aneuploidy and isochromosome formation in drug-resistant Candida albicans. Science 2006, 313, 367-370. [CrossRef] [PubMed]

64. Bouchonville, K.; Forche, A.; Tang, K.E.; Selmecki, A.; Berman, J. Aneuploid chromosomes are highly unstable during DNA transformation of Candida albicans. Eukaryot. Cell 2009, 8, 1554-1566. [CrossRef]

65. Forche, A.; Magee, P.T.; Selmecki, A.; Berman, J.; May, G. Evolution in Candida albicans populations during a single passage through a mouse host. Genetics 2009, 182, 799-811. [CrossRef]

66. Fan, H.; Chen, Y.; Duan, L.; Zhao, J.; Qin, C.; Li, H.; Sun, J.; Han, L. Comparison of Two Typing Methods for Characterization of Azole Resistance in Aspergillus fumigatus from Potting Soil Samples in a Chinese Hospital. Antimicrob. Agents Chemother. 2020, 64, e01578-19. [CrossRef] [PubMed]

67. Donato, M.L.; Park, S.; Baker, M.; Korngold, R.; Morawski, A.; Geng, X.; Tan, M.; Ip, A.; Goldberg, S.; Rowley, S.; et al. Clinical and laboratory evaluation of patients with SARS-CoV-2 pneumonia treated with high-titer convalescent plasma. JCI Insight 2021, 6, e143196. [CrossRef] [PubMed]

68. Arastehfar, A.; Shaban, T.; Zarrinfar, H.; Roudbary, M.; Ghazanfari, M.; Hedayati, M.T.; Sedaghat, A.; Ilkit, M.; Najafzadeh, M.J.; Perlin, D.S. Candidemia among Iranian Patients with Severe COVID-19 Admitted to ICUs. J. Fungi 2021, 7, 280. [CrossRef] [PubMed]

69. Silva, D.L.; Lima, C.M.; Magalhaes, V.C.R.; Baltazar, L.M.; Peres, N.T.A.; Caligiorne, R.B.; Moura, A.S.; Fereguetti, T.; Martins, J.C.; Rabelo, L.F.; et al. Fungal and bacterial coinfections increase mortality of severely ill COVID-19 patients. J. Hosp. Infect. 2021, 113, 145-154. [CrossRef] [PubMed] 